\title{
Diagnostic findings and successful management of central diabetes insipidus following a self- inflicted penetrating brain injury in a dog
}

\author{
Achados diagnósticos e tratamento bem-sucedido de \\ diabetes insípido central após uma lesão cerebral penetrante \\ autoinfligida em um cão
}

\author{
Andrew J. Lacqua* (D), Elizabeth A. Rozanski' ${ }^{1}$, Dylan A. Fry', Scott L. Gregorich' \& Amy F. Sato' \\ ' Veterinarian, Department of Clinical Sciences, Tufts University Cummings School of Veterinary Medicine, North Grafton, \\ Massachusetts, United States
}

\begin{abstract}
A 6-year-old $12 \mathrm{~kg}$ male neutered mixed breed dog presented in lateral recumbency with dysphoria and vocalization following a self-inflicted fork impalement injury. Computed tomography (CT) was performed which showed a penetrating wound through the right orbit, into the calvarium, and through the brain parenchyma. The dog was hospitalized with supportive care, sedatives, analgesia, antiepileptics, antiinflammatories, antibiotics, and desmopressin acetate (DDAVP) to control post-traumatic central diabetes insipidus (PTCDI) which developed during recovery. Magnetic resonance imaging (MRI) findings 16 days later revealed resolving ventricular hemorrhage and mild perilesional edema and inflammation. Normal mentation and ambulation slowly returned and 3 months later the dog was clinically normal. To the author's knowledge, this is the first report of a self-inflicted penetrating brain injury in a dog. This case demonstrates successful medical management of a dog with a traumatic brain injury (TBI) and PTCDI which is an uncommon occurrence in veterinary medicine.
\end{abstract}

Keywords: traumatic brain injury, desmopressin acetate, central diabetes insipidus.

\section{Resumo}

Um cão de 6 anos de idade, 12 kg, machos, castrados, sem raça definida, apresentou-se em decúbito lateral com disforia e vocalização após lesão autoinfligida por empalamento de um garfo. Foi realizada tomografia computadorizada (TC) que mostrou ferida penetrante através da órbita direita, na calvária e através do parênquima cerebral. O cão foi hospitalizado com cuidados de suporte, sedativos, analgesia, antiepilépticos, anti-inflamatórios, antibióticos e acetato de desmopressina (DDAVP) para controlar diabetes insípido central pós-traumático (PTCDI) que se desenvolveu durante a recuperação. Os achados da ressonância magnética (MRI) 16 dias depois revelaram hemorragia ventricular em resolução e edema perilesional leve e inflamação. O nível de consciência e a deambulação normais retornaram lentamente e 3 meses depois o cão estava clinicamente normal. Para o conhecimento do autor, este é o primeiro relato de uma lesão cerebral penetrante autoinfligida em um cão. Este caso demonstra o manejo médico bem-sucedido de um cão com lesão cerebral traumática (TCE) e PTCDI, que é uma ocorrência incomum em medicina veterinária.

Palavras-chave: lesão cerebral traumática, acetato de desmopressina, diabetes insípido central.

\section{Introduction}

Penetrating brain injuries are uncommon in veterinary medicine, with only a few cases reported in the literature (Burgisser \& Hintermann, 1967; Cottam \& Gannon, 2015; Daoust, 1991; McCandlish \& Ormerod, 1978; McKenzie et al., 2019; Park et al., 2010; Sauvé et al., 2012). Many of these reports involve foreign body penetration of the nasal cavity, nasopharynx, oropharynx, and foramen magnum and only one report involves penetration of the orbit. Diagnosis is often made using multiple imaging modalities including radiographs, CT, and MRI. Successful management can include surgical removal of the foreign body, anti-inflammatories, antibiotics, corticosteroids, analgesia, sedatives, anti-epileptics, supportive care, follow up imaging to monitor recovery progress, and time. Intracranial penetrating foreign bodies are also uncommon in human
How to cite: Lacqua, A. J., Rozanski, E. A., Dry, D. A., Gregorich, S. L., \& Sato, A. F. (2021). Diagnostic findings and successful management of central diabetes insipidus following a self-inflicted penetrating brain injury in a dog. Brazilian Journal of Veterinary Medicine, 43, e001521. https://doi. org/10.29374/2527-2179.bjvm001521

Received: May 14, 2021.

Accepted: November 04, 2021

\section{*Correspondence}

Andrew J. Lacqua

Department of Clinical Sciences, Tufts University Cummings School of Veterinary Medicine

North Grafton, MA, 01536, United States

E-mail: andrewlacquadvm@gmail.com 
medicine. Often involving both missile and non-missile foreign bodies like chopsticks, bullets, shell fragments, and knives they are a significant cause of mortality in young people (Alao \& Waseem, 2021; Park et al., 2006; Schreckinger et al., 2011). Because penetrating brain injuries occur rapidly and final neurological outcome is predicted by secondary brain injury, the practitioner's focus is shifted toward treating secondary brain injury and conditions that can worsen overall outcome like hypotension, anemia, hypoxia, and hyperpyrexia. In human medicine, surgical management typically involves foreign body removal, craniotomy, hematoma evacuation, and conservative debridement of damaged brain tissue. Medical management often involves endotracheal intubation to maintain adequate ventilation and maintenance of both intracranial pressure and cerebral perfusion pressure (Alao \& Waseem, 2021).

Another important condition associated with, and possible outcome of, TBI is central diabetes insipidus (CDI). CDI develops after impaired secretion of anti-diuretic hormone (ADH) from the posterior pituitary gland, due to destruction of the neurons of the hypothalamus/posterior pituitary axis, resulting in polyuria and subsequent hypernatremia and plasma hyperosmolality (Feldman \& Nelson, 2015; Garrahy et al., 2019). In human medicine CDI is caused by various neurosurgical conditions including neoplasia and cysts, autoimmune or inflammatory disease, vascular and infiltrative disease, and TBI (Garrahy et al., 2019). CDI is reported to occur in $20 \%$ of human TBI cases, with persistent CDI carrying worse prognosis (Agha et al., 2004; Hannon et al., 2013). For this, PTCDI is extensively studied in human medicine, but it is rarely encountered or described in veterinary medicine.

To date and to the author's knowledge, there are only five case reports involving PTCDI and dogs: two reports describing CDI following TBI, one report describing CDI following cardiopulmonary arrest, one report describing CDI after transsphenoidal surgery in a dog with Cushing's disease, and one report describing the developing of hypothalamic-pituitary axis deficiency following TBI (Authement et al., 1989; Bellis et al., 2015; Croton et al., 2019; Foley et al., 2009; Teshima et al., 2011). Of these reported cases of CDI, only two describe PTCDI.

This report describes the use of both CT and MRI to confirm a transient penetrating intracranial foreign body which entered the right orbit and caused brain injury. It also details the medical management of a self-inflicted penetrating brain injury and PTCDI in a dog, which is not often described in the veterinary medical literature.

\section{Case report}

A 6-year-old $12 \mathrm{~kg}$ male neutered mixed breed dog presented for diagnosis and treatment of a self-inflicted penetrating fork impalement injury through the right orbit and presumably into the brain. On initial presentation, the dog was laterally recumbent, dysphoric, and vocalizing. Physical examination showed ptyalism, apparent pain, and a puncture wound through the lateral aspect of the right orbit with bloody discharge and severe chemosis. Neurological examination identified dysphoria, mental dullness, and vocalization. The dog was non-ambulatory tetraparetic with right-sided proprioceptive deficits, including spontaneous knuckling of the right hindlimb, a right head turn, absent palpebral reflex laterally in the right eye (OD), absent menace response OD, absent pupillary light reflex OD, and ventrolateral strabismus in the left eye (OS). The dog had no conscious response to nasal or mandibular stimuli on either side of the face. The dog was able to stand with support and had adequate muscle tone in all four limbs. Ophthalmological examination showed ventrolateral strabismus OS and miosis in both eyes (OU) with mild anisocoria (OS > OD). Neuroanatomical localization was the forebrain, which was consistent with the history provided. Laboratory testing showed hyperchloridemia $(125 \mathrm{mmol} / \mathrm{L}$; reference interval, 109-120 mmol/L), hyperlactatemia ( $5 \mathrm{mmol} / \mathrm{L}$; reference interval, 0-2 mmol/L), hypernatremia (157 mmol/L; reference interval, 140-154 mmol/L), hyperglycemia (180 mg/dL; reference interval, 80-120 mg/dL), hypokalemia (3.4 mmol/L; reference interval, 3.6-4.8 mmol/L), and hemoconcentration (53\%; reference interval, 38-48\%).

Emergency CT of the brain was performed, using a Toshiba Aquilion 16-slice CT scanner (Toshiba Medical Systems, Tokyo, Japan), under general anesthesia with fentanyl (4 mcg/kg IV), propofol (8 mg/kg IV), a continuous rate infusion (CRI) of fentanyl ( $0.2 \mathrm{mcg} / \mathrm{kg} / \mathrm{min}$ IV), and sevoflurane for maintenance. Post-contrast images were acquired following administration of $600 \mathrm{mgI} / \mathrm{kg}$ of Iohexol-300. Images were reconstructed (slice thickness and index $=2 \mathrm{~mm}$ ) in 
transverse, sagittal, and dorsal planes using sharp bone and soft tissue head algorithms. Images showed moderate exophthalmos of the right eye, marked soft tissue swelling around the right globe extending into the retrobulbar space; and a linear hyperattenuating tract consistent with acute hemorrhage running through the right orbit sparing the globe, penetrating the right palatine bone, and coursing through the right frontal lobe extending into the left frontal lobe. There was hemorrhage present in the lateral, third, and fourth ventricles (Figure 1).

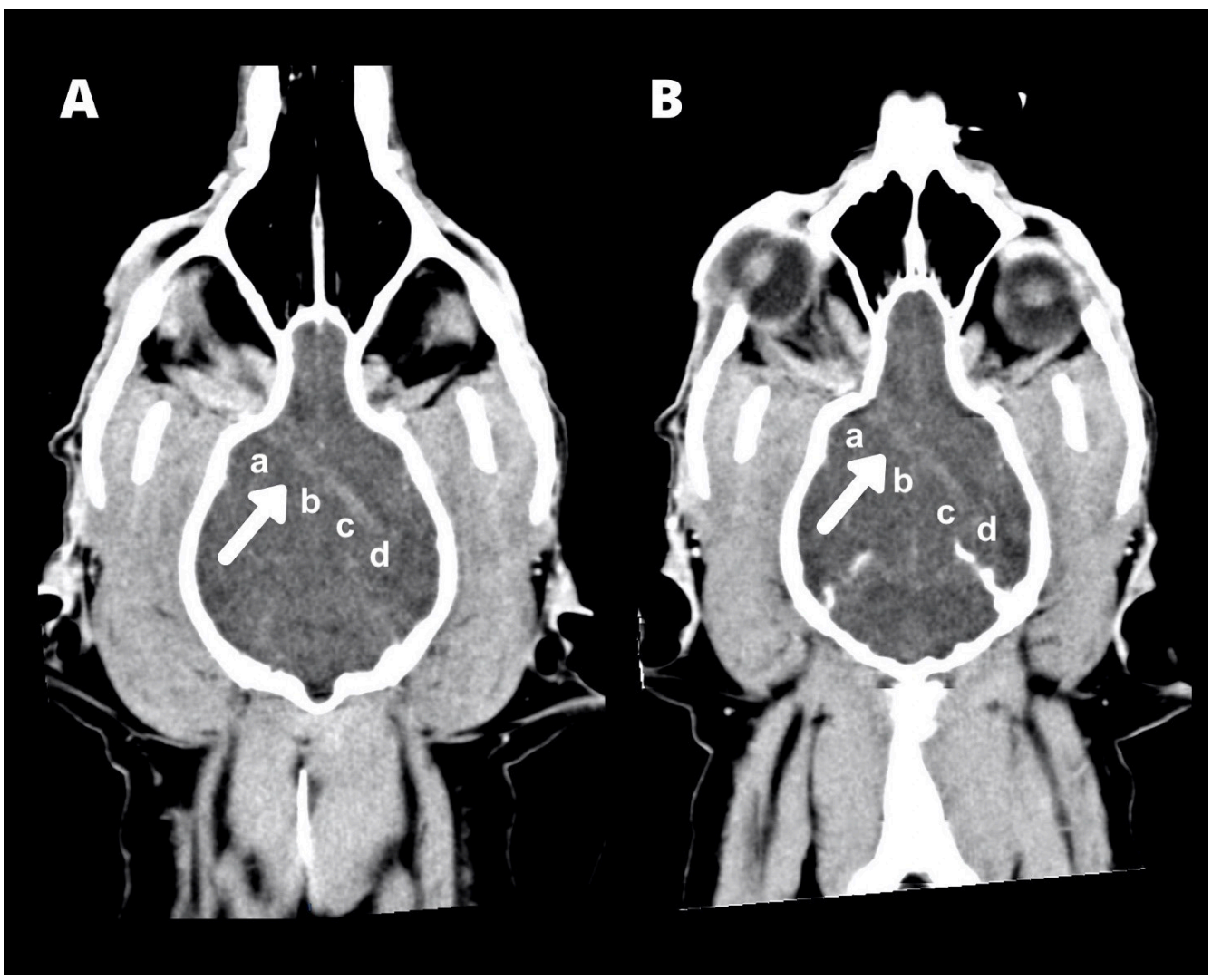

Figure 1. Initial (A) dorsal CT image (soft tissue window) and (B) dorsal oblique CT image (soft tissue window) at the level of the palatine bone. A hyperattenuating linear tract (arrows) coursing from the retrobulbar space through the right palatine bone in a right rostrolateral to caudomedial direction. This linear tract continues through the right ventral aspect of the cerebral cortex (a), the right internal capsule (b), and the rostral horns of the lateral ventricles (c). It crosses midline and terminates caudally in the left thalamus (d).

The dog was recovered from anesthesia and hospitalized with supportive care. The treatment plan and neurological examination were re-evaluated at least twice a day and included fentanyl CRI (2 mcg/kg/h IV), dexmedetomidine CRI ( $1.5 \mathrm{mcg} / \mathrm{kg} / \mathrm{h} \mathrm{IV})$, enrofloxacin ( $7.5 \mathrm{mg} / \mathrm{kg} \mathrm{IV}$, q12h), metronidazole (10 mg/kg IV, q12h), cefotaxime (30 mg/kg IV, q8h), levetiracetam (25 mg/kg IV, q8h), dexamethasone SP (0.08 mg/kg IV, q12h; $1 \mathrm{mg} / \mathrm{kg} /$ day prednisone equivalent), neopolybac ophthalmic ointment (1 drop, OD, q6h), diazepam CRI (0.2 mg/kg/h IV), trazadone (1.8 mg/kg per os [PO], q8h), famotidine (1 mg/kg IV, q12h), and cerenia (13.5 mg/kg IV, q24h). Intravenous fluid therapy included a tapering schedule of Lactated Ringer's Solution (LRS) initially given at a rate of $85 \mathrm{ml} / \mathrm{h}$ (2.5x maintenance rate), then $50 \mathrm{ml} / \mathrm{h}$ (1.5x maintenance rate), and finally $35 \mathrm{ml} / \mathrm{h}$ (maintenance rate) after one week of hospitalization. Dexmedetomidine, diazepam, and fentanyl boluses were given as needed for breakthrough episodes of dysphoria. After two days the fentanyl CRI was discontinued due to persistent extreme dysphoria and was replaced with methadone (0.1 mg/kg IV, q6h). After one week of hospitalization, cefotaxime was discontinued, and ceftriaxone (50 mg/kg SQ, q12h) was started to decrease the number of intravenous medications the dog was receiving. 
At the beginning of hospitalization, the dog developed right-sided proprioceptive deficits, likely secondary to the forebrain injury; and hyposthenuria, polyuria, and hypernatremia which supported the possible development of post-traumatic CDI (Table 1). The dog was started on DDAVP (0.1 mg/ml; 1 drop, OU, q12h). The dog's serum sodium level and urine specific gravity (USG) were monitored frequently for signs of improvement (Na consistently $<154 \mathrm{mmol} / \mathrm{L}$ and USG between 1.015-1.045) and after 5 days the DDAVP was discontinued (Table 1).

Table 1. Plasma sodium concentrations (reference interval, 140-154 mmol/L) and urine specific gravity measurements (reference interval, 1.015-1.045) during hospitalization. DDAVP was started on day three of hospitalization and discontinued after day five.

\begin{tabular}{ccc}
\hline Day of Hospitalization & $\begin{array}{c}\text { Plasma Na concentration } \\
(\mathrm{mmol} / \mathbf{L})\end{array}$ & Urine specific gravity (USG) \\
\hline 1 & 157 & $\cdots$ \\
2 & 158 & $\cdots$ \\
3 & 162 & $\cdots$ \\
4 & 164 & 1.008 \\
5 & 160 & 1.008 \\
6 & 154 & 1.007 \\
7 & 154 & 1.009 \\
8 & 144 & 1.011 \\
9 & 148 & $\cdots$ \\
10 & 152 & $\cdots$ \\
11 & 149 & 1.028 \\
12 & 150 & 1.028 \\
13 & 150 & 1.045 \\
14 & 150 & 1.060 \\
15 & 165 & 1.060 \\
16 & 162 & 1.050 \\
17 & 150 & 1.028 \\
\hline
\end{tabular}

After one week of hospitalization the dog had complete return of conscious nasal sensation, was no longer dysphoric, began eating, and regained enough strength to walk unassisted, although the dog would intermittently lean to the left. With overall clinical improvement and the hindrance excessive sedation could have on mentation and ambulation methadone, dexmedetomidine, and diazepam CRI were discontinued. As mentation improved daily, the dog was transitioned to oral medications including extended release levetiracetam (37 mg/kg PO, q12h), prednisone (0.7 mg/kg PO, q24h), famotidine (0.7 mg/kg PO, q12h), cefpodoxime (11 mg/kg PO, q24), enrofloxacin (10 mg/kg PO, q24), and metronidazole (9 mg/kg PO, q12h) and intravenous fluid therapy was discontinued. The dog was also transitioned to LRS (300ml, SQ, q12h) to control volume depletion and dehydration.

The dog's neurological status noticeably improved after 16 days, and only mild right-sided proprioceptive deficits were noted. At this time an MRI was performed using a high-field scanner (1.5- Tesla unit, Siemens MagnetomSymphonyMaestro Class, Erlangen, Germany). Precontrast images of the brain were acquired using the following sequences: sagittal T2W TSE, transverse T2w TSE, T2* W GRE, T2w FLAIR, and T1w SE, and a diffusion protocol. After intravenous administration of $0.1 \mathrm{mmol} / \mathrm{kg}$ of gadopentetate dimeglumine (Magnevist, Bayer Healthcare Pharmaceuticals, Inc, Wayne, NJ) T1w SE images were acquired in transverse, sagittal, and dorsal planes. Images showed a linear tract coursing from the right orbit and crossing the right and left forebrain consistent with subacute hemorrhage. The intraventricular hemorrhage was resolved and there was only mild perilesional edema and inflammation (Figure 2). 


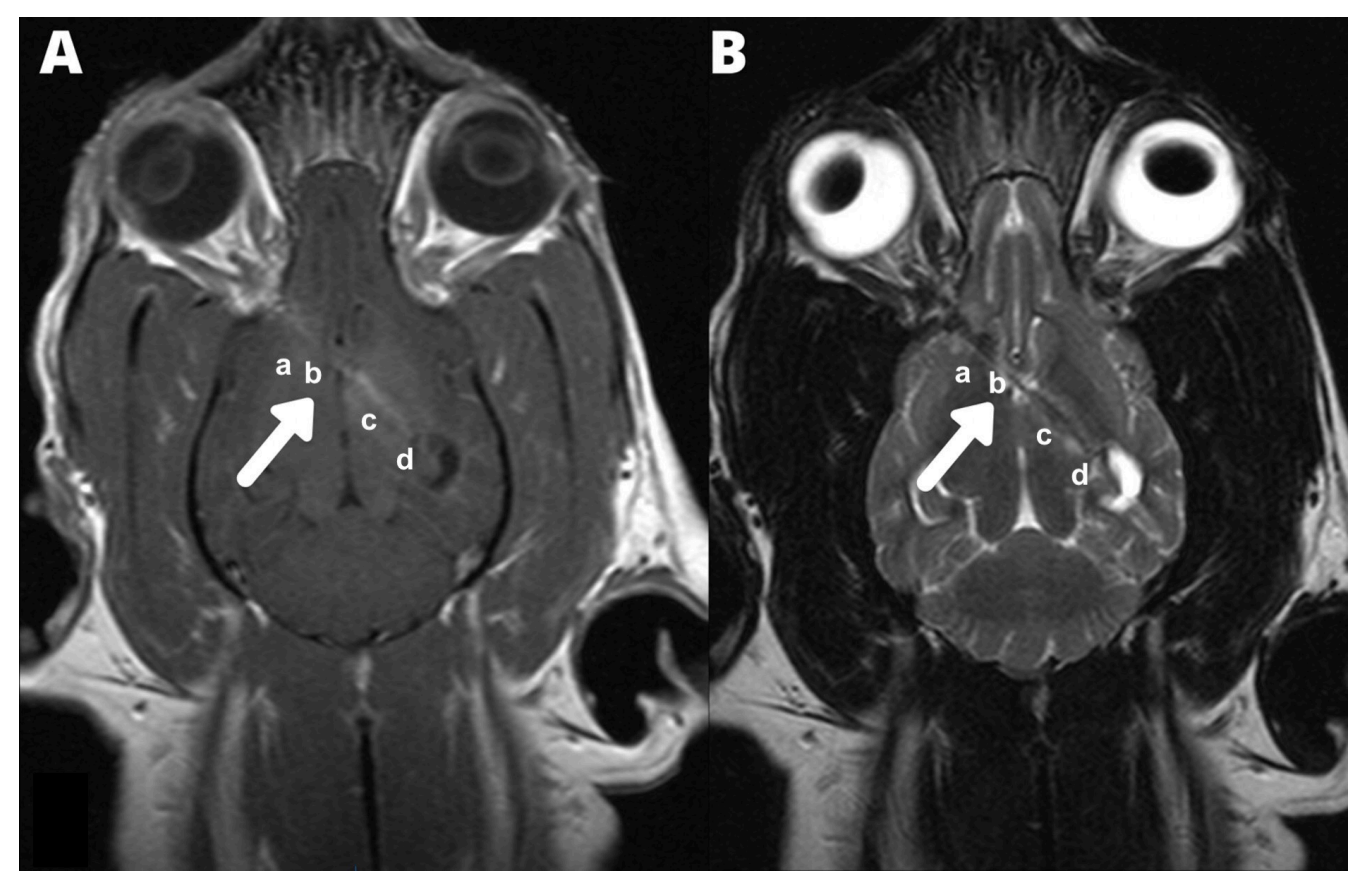

Figure 2. Follow up MRI images obtained 16 days after the penetrating brain injury. (A) Dorsal T1-weighted image at the level of the palatine bone and (B) dorsal T2-weighted image. A T2w/Fluid attenuated inversion recovery (FLAIR)/Gradient echo sequences (GRE) hypointense and Tlw hyperintense linear tract (arrows) with T2w/FLAIR hyperintense peripheral margins coursing through the right ventral cerebral cortex (a) to the right ventral internal capsule (b) ventral to the rostral horns of the lateral ventricles (c). The linear tract then crosses midline and terminates caudally in the left thalamus (d)

The dog was discharged after 18 days with greatly improved neurological function and only mild right-sided proprioceptive deficits. The dog remained nonvisual in the right eye. Medications at discharge included extended release levetiracetam (37 mg/kg PO, q12h for at least 6 months), metronidazole ( $9 \mathrm{mg} / \mathrm{kg}$ PO, q12h for 2 months), enrofloxacin (10 mg/kg PO, q24h for 2 months), cefpodoxime (11 mg/kg PO, q24h for 2 months), a tapering prednisone regime (0.4 mg/kg PO, q24h for 1 week; then $0.2 \mathrm{mg} / \mathrm{kg}$ PO, q24h for 1 week; then $0.2 \mathrm{mg} / \mathrm{kg}$ PO, q24h every other day for 1 week), maropitant (1.8 mg/kg PO, q24h) as needed, and famotidine (0.7 mg/kg PO, q12h) for the duration of prednisone administration. The owner was instructed to avoid giving the dog excess dietary sodium because of the PTCDI that had developed.

At one week recheck physical examination was unremarkable, neurological examination showed mild right sided proprioceptive deficits, and vision in the right eye was improving. At recheck 1.5 months later, right eye vision was greatly improved, and the dog had only mild right sided proprioceptive deficits. At final recheck 3 months after discharge, physical and neurological examination were normal. The dog was discharged with trazodone $(3.7 \mathrm{mg} / \mathrm{kg}$ PO) as needed and extended release levetiracetam (37 mg/kg PO, q12h) until further instruction.

The dog was seizure free and clinically normal for the next four years. In December 2019 the dog presented to Bay State Veterinary Emergency Services for humane euthanasia due to refractory seizure activity that began earlier that month.

\section{Discussion}

Initial CT images showed a puncture fracture through the right palatine bone and a linear tract which traveled through both hemispheres of the forebrain. Because the dog suffered a penetrating injury to the forebrain, the area of the brain that plays a role in processing cognitive, sensory, and voluntary motor activities; dysphoria, mental dullness, proprioceptive deficits, tetraparesis, and cranial nerve damage were seen on presentation. The penetrating brain injury also led to hemorrhage within the brain parenchyma that collected within the ventricles, the 
system within the brain that collects and drains cerebrospinal fluid that bathes the brain, meninges, and spinal cord. This allowed the blood to drain out of the cranium rather than collect within the skull and cause an increase in pressure or compression. Given these findings, and to help reduce potential secondary inflammatory reactions and intracranial swelling, the dog was started on an anti-inflammatory dose of prednisone. The dog was also given intravenous sedatives, analgesia, antiepileptic medications, and supportive care to manage clinical signs, mitigate seizure risk, and ease the acute episodes of dysphoria, vocalization, and thrashing that had occurred the first few nights of hospitalization.

Early on during hospitalization the dog became hyposthenuric, hypernatremic, and polyuric suggesting the potential development of PTCDI, which is uncommonly reported in veterinary medicine. Authement et al. (1989) was the first to describe CDI secondary to TBI in a dog who sustained a skull fracture at the level of the pituitary gland after being hit by a car. While CDI is most often seen secondary to TBI in dogs and cats, it has also been seen following cardiopulmonary arrest in an 8-week-old Golden Retriever (Bellis et al., 2015; Campbell \& Bredhauer, 2005; Foley et al., 2009). In human medicine, PTCDI is extensively studied and associated with significantly increased morbidity and mortality, especially when developing early after TBI (Capatina et al., 2015). Additionally, hypernatremia, a main feature of CDI, is shown to significantly increase the risk of early mortality in patients with TBI (Vedantam et al., 2017). In this case, it is suspected CDI developed secondary to the penetrating forebrain damage, as it contains the hypothalamus which produces vasopressin $(\mathrm{ADH})$ that normally controls sodium retention and water excretion by the body (Feldman \& Nelson, 2015). After penetration of the forebrain, it is presumed subsequent edema, inflammation, and hemorrhage around the hypothalamus resulted in inadequate ADH release and the development of CDI. For this, the dog was given DDAVP drops on the conjunctiva for 1 week, after which Na levels and USG normalized.

DDAVP has been successfully used in other reports involving PTCDI in dogs (Authement et al., 1989; Bellis et al., 2015; Croton et al., 2019; Foley et al., 2009). In these cases, response to DDAVP therapy was confirmed with a combination of increased USG, increased urine osmolality, decreased serum osmolality, and normalized serum $\mathrm{Na}$. The commonalities among these reports in assessing response to DDAVP therapy are increased USG and normalized serum Na. Similarly in this report, response to DDAVP therapy was assessed with a decrease in serum sodium and increase in USG two days after starting DDAVP therapy (Table 1). Response to DDAVP therapy in people with CDI can also be confirmed by an increase in urine osmolality and decrease in serum osmolality (Capatina et al., 2015). In this report, serum and urine osmolality were not assessed. Additionally, a water deprivation test or modified water deprivation can be used to diagnose CDI (Agha et al., 2005). However, given the traumatic nature of this case and the dog's poor initial neurological status, these diagnostic tests would be inappropriate.

CDI was suspected in this patient due to rapid onset of hypernatremia following TBI that responded poorly to fluid therapy. Croton et al. (2019) described a similar case involving a dog with TBI and hypernatremia which did not respond to fluid therapy but did respond to DDAVP therapy, increasing the suspicion for CDI. Historically, there is a lack of consensus regarding the definition of CDI in human and veterinary medicine. Despite this, in human medicine it is agreed that CDI involves polyuria, hypernatremia, and hyperosmolality. Typically, polyuria is defined as urine volume $>2 \mathrm{ml} / \mathrm{kg} / \mathrm{h}$, urine osmolality < $300 \mathrm{mOsm} / \mathrm{kg}$, plasma osmolality > $300 \mathrm{mOsm} / \mathrm{kg}$, and serum sodium > 143 mmol/L (Seckl \& Dunger, 1989; Tudor \& Thompson, 2019). In veterinary medicine, there is a paucity of reports offering a general definition of CDI. However, there is a report describing the development and management of CDI following transsphenoidal surgery that classifies CDI based on the requirement for DDAVP, and this requirement is defined as either a plasma sodium concentration $>160 \mathrm{mEq} / \mathrm{l}$ or a USG less than or equal to 1.005 (Teshima et al., 2011). In this report, the dog was hypernatremic (serum $\mathrm{Na}>160 \mathrm{mEq} / \mathrm{L}$ ) and it did respond favorably to DDAVP therapy with a normalized serum Na concentration and increased USG. Therefore, by the definition of CDI set forth by Teshima et al. (2011) it can be presumed that the dog in this report did have CDI following TBI. Possibly defining CDI based on the requirement for DDAVP therapy has also been discussed in other reports of traumatically induced CDI in dogs (Authement et al., 1989; Bellis et al., 2015; Croton et al., 2019; Foley et al., 2009; Teshima et al., 2011).

Once the CDI resolved and the breakthrough episodes of dysphoria were under control the dog's neurological function and mentation gradually improved the following week. MRI performed 16 days after presentation showed near resolution of the ventricular hemorrhage and mild perilesional edema and inflammation. These improvements coincided with overall 
improved mentation and only mild right-sided proprioceptive deficits. MRI also showed a larger void of brain tissue and scar on the left side, which fits with the dogs predominantly right-sided neurological deficits (indicating left forebrain injury), although the meat lifting fork entered the right side of the brain and crossed both hemispheres.

Prophylactic antiepileptic medication was prescribed indefinitely and for the next four years the dog was seizure free. However, in December 2019 the dog began having grand mal seizures, despite anti-epileptic medications, became acutely blind, and was eventually humanely euthanized due to concerns for quality of life. It is likely the late onset seizures were more likely related to a structural brain lesion like a tumor, however, without an MRI this cannot be certain. The seizures could perhaps be secondary to scar formation from the TBI, a vascular event, infection, or late onset epilepsy.

An injury such as this can be treated generally with supportive care, management of comorbid conditions that can exacerbate secondary brain injury, and time. It is critically important to monitor serum Na concentration following TBI since all TBI dogs in one study with a serum sodium concentration of $>160 \mathrm{mmol} / \mathrm{L}$ were considered non-survivors (Riese et al., 2018). Additionally, USG, urine output, urine osmolality, and serum osmolality should also be monitored throughout hospitalization following TBI since the development of CDI warrants therapy with DDAVP. DDAVP is often given orally in human medicine, although it can also be given intranasally and parenterally (Garrahy \& Thompson, 2020). In veterinary medicine it can be applied topically to the conjunctiva (Croton et al., 2019). Additionally, seizure medications can also be considered - during hospitalization, for an extended period, or lifelong - as TBI can lead to life-long seizure disorders (Elias et al., 2019).

It is important to consider the prognosis of the dog in this case report if DDAVP was not given. PTCDI is an uncommon condition in people, and in survivors the condition can either be transient, lasting a few days to several weeks, or it can be permanent, requiring lifelong medical therapy (Capatina et al., 2015). In veterinary medicine there is no scientific evidence describing the shortterm use of DDAVP to improve outcome in dogs with PTCDI. However, two case reports described the short-term use of DDAVP to treat suspected CDI in dogs over the course of seven days and nine days (Bellis et al., 2015; Croton et al., 2019). Furthermore, another case report described increased urine concentration within 24 hours after a single dose of DDAVP in a dog with CDI, which further supported the diagnosis of CDI (Foley et al., 2009). It is presumed in these cases that prognosis was positively affected due to DDAVP administration. Here, the dog was treated for five days after which time USG and serum Na concentration improved, potentially providing evidence for the positive effect of DDAVP administration on overall prognosis.

\section{Conclusions}

Despite the lack of consensus regarding the definition of CDI in dogs, the presence of TBI, the rapid development of hypernatremia, and favorable response to DDAVP therapy suggested the development of CDI in the dog reported here. Follow up MRI showed a resolution of intracranial hemorrhage, edema, and inflammation which coincided with improvement in neurological status. Serum Na concentration and USG also improved following the administration of DDAVP conjunctivally. With intensive supportive care, pain management, close monitoring of fluid balance; and medical therapy including DDAVP, anticonvulsants, and corticosteroids this case of PTCDI resolved with great outcome. It is important to measure urine output and volume, urine specific gravity, serum Na concentration, serum osmolality, and urine osmolality in cases of TBI since CDI can develop, is associated with poor outcome, and requires therapy with DDAVP. Furthermore, more discussion is required to come to a consensus regarding the definition of CDI in the canine patient since it is an important, potential sequelae of TBI.

\section{Acknowledgements}

We acknowledge the administration of the Foster Hospital for Small Animals and Department of Clinical Sciences, who financially supported the MRI scan, and the Travis Fund, which supported on-going hospitalization during the dog's recovery. All of the work for this case report was completed at Tufts University Cummings School of Veterinary Medicine. 


\section{Ethics statement}

All procediments were consented by the animal owner.

\section{Financial support}

None.

\section{Conflict of interests}

AJL, EAR, DAD, SLG, AFS - No conflict of interest.

\section{Authors' contributions}

AJL, EAR, DAD, SLG, AFS - Conception and design of work, drafting and revising of work, final approval of version to be publish, agreement of accuracy and integrity of total work.

\section{Availability of complementary results}

This case report has no complementary results or information

The study was carried out at Department of Clinical Sciences, Tufts University Cummings School of Veterinary Medicine, North Grafton, MA, United States.

\section{References}

Agha, A., Rogers, B., Mylotte, D., Taleb, F., Tormey, W., Phillips, J., \& Thompson, C. J. (2004). Neuroendocrine dysfunction in the acute phase of traumatic brain injury. Horumon To Rinsho, 60(5), 584-591. http://dx.doi. org/10.1111/j.1365-2265.2004.02023.x. PMid:15104561.

Agha, A., Sherlock, M., Phillips, J., Tormey, W., \& Thompson, C. J. (2005). The natural history of post-traumatic neurohypophysial dysfunction. European Journal of Endocrinology, 152(3), 371-377. http://dx.doi.org/10.1530/ eje.1.01861. PMid:15757853.

Alao, T., \& Waseem, M. (2021). Penetrating head trauma. Treasure Island: StatPearls Publishing.

Authement, J. M., Boudrieau, R. J., \& Kaplan, P. M. (1989). Transient, traumatically induced, central diabetes insipidus in a dog. Journal of the American Veterinary Medical Association, 194(5), 683-685. PMid:2925484.

Bellis, T., Daly, M., \& Davidson, B. (2015). Central diabetes insipidus following cardiopulmonary arrest in a dog. Journal of Veterinary Emergency and Critical Care, 25(6), 745-750. http://dx.doi.org/10.1111/vec.12398. PMid:26473756.

Burgisser, H., \& Hintermann, J. (1967). Cerebral damages due to foreign bodies from the nasal cavity in the dog. Schweizer Archiv fur Tierheilkunde, 109(10), 537-538. PMid:5628640.

Campbell, F. E., \& Bredhauer, B. (2005). Trauma-induced central diabetes insipidus in a cat. Australian Veterinary Journal, 83(12), 732-735. http://dx.doi.org/10.1111/j.1751-0813.2005.tb11578.x. PMid:16395935.

Capatina, C., Paluzzi, A., Mitchell, R., \& Karavitaki, N. (2015). Diabetes insipidus after traumatic brain injury. Journal of Clinical Medicine, 4(7), 1448-1462. http://dx.doi.org/10.3390/jcm4071448. PMid:26239685.

Cottam, E. J., \& Gannon, K. (2015). Migration of a sewing needle foreign body into the brainstem of a cat. Journal of Feline Medicine and Surgery Open Reports, 1(1), 1-5. http://dx.doi.org/10.1177/2055116915589841. PMid:28491366.

Croton, C., Purcell, S., Schoep, A., \& Haworth, M. (2019). Successful treatment of transient central diabetes insipidus following traumatic brain injury in a dog. Case Reports in Veterinary Medicine,2019, 3563675. http:// dx.doi.org/10.1155/2019/3563675. PMid:31179153.

Daoust, P. Y. (1991). Porcupine quill in the brain of a dog. The Veterinary Record, 128(18), 436. http://dx.doi. org/10.1136/vr.128.18.436-a. PMid:1853545.

Elias, N., Rotariu, A. M., \& Grave, T. (2019). Traumatic brain injury in dogs and cats. Companion Animal, 24(9), 480-487. http://dx.doi.org/10.12968/coan.2019.0015.

Feldman, E. C., \& Nelson, R. W. (2015). Canine and feline endocrinology and reproduction (4th ed., pp. 2-43). St. Louis: Eds Saunders-Elsevier.

Foley, C., Bracker, K., \& Drellich, S. (2009). Hypothalamic-pituitary axis deficiency following traumatic brain injury in a dog: Case report. Journal of Veterinary Emergency and Critical Care, 19(3), 269-274. http://dx.doi. org/10.1111/j.1476-4431.2009.00409.x. PMid:19691512.

Garrahy, A., Moran, C., \& Thompson, C. J. (2019). Diagnosis and management of central diabetes insipidus in adults. Horumon To Rinsho, 90(1), 23-30. http://dx.doi.org/10.1111/cen.13866. PMid:30269342.

Garrahy, A., \& Thompson, C. J. (2020). Management of central diabetes insipidus. Best Practice \& Research. Clinical Endocrinology \& Metabolism, 34(5), 101385. http://dx.doi.org/10.1016/j.beem.2020.101385. PMid:32169331. 
Hannon, M. J., Crowley, R. K., Behan, L. A., O'Sullivan, E. P., O’Brien, M. M., Sherlock, M., Rawluk, D., O’Dwyer, R., Tormey, W., \& Thompson, C. J. (2013). Acute glucocorticoid deficiency and diabetes insipidus are common after acute traumatic brain injury and predict mortality. The Journal of Clinical Endocrinology and Metabolism, 98(8), 3229-3237. http://dx.doi.org/10.1210/jc.2013-1555. PMid:23690314.

McCandlish, I. A., \& Ormerod, E. J. (1978). Brain abscess associated with a penetrating foreign body. The Veterinary Record, 102(17), 380-381. http://dx.doi.org/10.1136/vr.102.17.380. PMid:347686.

McKenzie, J., Cooper Murphy, M., Broome, C., Tayari, H., \& Gutierrez-Quintana, R. (2019). Imaging characteristics and treatment of a penetrating brain injury caused by an oropharyngeal foreign body in a dog. Veterinary Radiology \& Ultrasound, 60(3), E24-E28. http://dx.doi.org/10.1111/vru.12527. PMid:28726346.

Park, S. H., Cho, K. H., Shin, Y. S., Kim, S. H., Ahn, Y. H., Cho, K. G., \& Yoon, S. H. (2006). Penetrating craniofacial injuries in children with wooden and metal chopsticks. Pediatric Neurosurgery, 42(3), 138-146. http://dx.doi. org/10.1159/000091855. PMid:16636613.

Park, S. H., Park, J., Kim, J. M., Kim, J. H., Son, J., Chang, D., Choi, S. H., \& Kim, G. (2010). Penetrating cranial injury due to gunshot in a dog: A case report. Veterinarni Medicina, 55(5), 253-257. http://dx.doi.org/10.17221/2995-VETMED.

Riese, F., Rohn, K., Hoppe, S., \& Tipold, A. (2018). Hypernatremia and coagulopathy may or may not be useful clinical biomarkers in dogs with head trauma: A retrospective study. Journal of Neurotrauma, 35(23), 28202826. http://dx.doi.org/10.1089/neu.2016.4620. PMid:30088439.

Sauvé, C., Sereda, N., \& Sereda, C. (2012). Identification of an intra-cranial intra-axial porcupine quill foreign body with computed tomography in a canine patient. The Canadian Veterinary Journal, 53(2), 187-189. PMid:22851782.

Schreckinger, M., Orringer, D., Thompson, B. G., La Marca, F., \& Sagher, O. (2011). Transorbital penetrating injury: Case series, review of the literature, and proposed management algorithm. Journal of Neurosurgery, 114(1), 53-61. http://dx.doi.org/10.3171/2010.8.JNS10301. PMid:20868210.

Seckl, J., \& Dunger, D. (1989). Postoperative diabetes insipidus: Correct interpretation of water balance and electrolyte data essential. British Medical Journal, 298(6665), 2-3. http://dx.doi.org/10.1136/bmj.298.6665.2. PMid:2492841.

Teshima, T., Hara, Y., Taoda, T., Teramoto, A., \& Tagawa, M. (2011). Central diabetes insipidus after transsphenoidal surgery in dogs with cushing's disease. The Journal of Veterinary Medical Science, 73(1), 33-39. http://dx.doi. org/10.1292/jvms.10-0129. PMid:20736519.

Tudor, R. M., \& Thompson, C. J. (2019). Posterior pituitary dysfunction following traumatic brain injury: Review. Pituitary, 22(3), 296-304. http://dx.doi.org/10.1007/s11102-018-0917-z. PMid:30334138.

Vedantam, A., Robertson, C., \& Gopinath, S. (2017). Morbidity and mortality associated with hypernatremia in patients with severe traumatic brain injury. Neurosurgical Focus, 43(5), E2. http://dx.doi.org/10.3171/2017.7.FOCUS17418. PMid:29088954. 